\title{
IMPLEMENTASI KOMBINASI METODE AHP DAN SAW DALAM PENDUKUNG KEPUTUSAN PENENTUAN KREDIT PERUMAHAN RAKYAT
}

\author{
Yustina Meisella Kristania \\ Program Studi Sistem Informasi \\ Sekolah Tinggi Manajemen Informatika dan Komputer Nusa Mandiri Jakarta \\ (STMIK Nusa Mandiri) \\ Email : yustina760@gmail.com
}

\begin{abstract}
ABSTRAK
Pentingnya rumah dan lingkungan yang kondusif membuat banyak dari pengembang memberikan tawaran kriteria pemilihan rumah. Untuk itu, diperlukan perangkingan data perumahan yang akan membantu mengetahui kelayakan dalam berbagai alternatif pilihan, sehingga keputusan dapat diambil oleh calon pembeli. Bobot pada setiap kriteria ditentukan menggunakan metode Analytic Hierarchy Process dan untuk menentukan rangking data perumahan menggunakan metode Simple Additive Weighting. Tujuan yang ingin dicapai dalam penelitian ini adalah untuk menghasilkan suatu implementasi dalam mendukung keputusan penentuan kredit perumahan rakyat berdasarkan data perumahan yang ada di kota Purwokerto. Hasil akhirnya adalah bahwa implementasi pada penentuan kredit perumahan rakyat dapat memudahkan calon konsumen dalam melakukan pembelian rumah berdasarkan harga, desain, tipe rumah, lokasi dan fasilitas hingga akses dari jalan.
\end{abstract}

Kata Kunci: Analytic Hierarchy Process, Simple Additive Weighting, Kredit Perumahan.

\begin{abstract}
The importance of a home and a conducive environment is created from. For that, it needs a residential data ranking that will help determine the feasibility in various alternative options, so that decisions can be taken by prospective customers. Weights on each criterion. Method to determine data rank data using Simple Additive Weighting method. The goal to be achieved in this research is to produce an implementation in determining the decision of housing ownership based on existing housing data in the city of Purwokerto. The end result is the implementation on the determination of public housing loans can facilitate prospective customers in making purchases of houses based on price, design, type of house, location and facilities until access from the road.
\end{abstract}

Keywords: Analytic Hierarchy Process, Simple Additive Weighting, Housing loans. 


\section{PENDAHULUAN}

Rumah adalah kebutuhan pokok yang berfungsi sebagai tempat tinggal. Untuk saat ini kebutuhan akan sebuah rumah semakin meningkat, terlihat dari banyaknya bank yang menawarkan program kredit kepemilikan rumah (KPR) dengan berbagai jenis, syarat dan ketentuan. Purwokerto sebagai pusat pemerintahan Kabupaten Banyumas merupakan salah satu kota yang nyaman untuk tempat tinggal ditunjang dengan perekonomian yang juga terus berkembang. Pentingnya rumah dan lingkungan yang kondusif membuat banyak dari pengembang yang memberikan tawaran kriteria pemilihan rumah mulai dari harga, desain, tipe rumah, lokasi, fasilitas hingga akses dari jalan. Fasilitas kredit perbankan yang memungkinkan memiliki rumah dalam waktu singkat, merupakan salah satu faktor bisnis perumahan berkembang di Purwokerto. Konsumen yang hendak membeli rumah memiliki banyak pertimbangan sebelum memutuskan membeli, melihat hal tersebut maka konsumen perlu melakukan pemilihan yang tepat agar sesuai dengan yang diinginkan. Untuk dapat memenuhi hal tersebut, diperlukan informasi data perumahan disertai dengan perangkingan yang akan membantu mengetahui kelayakan dalam berbagai alternatif pilihan perumahan yang ditawarkan, sehingga keputusan dapat diambil oleh calon konsumen sesuai dengan kebutuhan, berdasarkan data perumahan yang ada di Purwokerto menggunakan metode Analytic Hierarchy Process dan metode Simple Additive Weighting. Berdasarkan dari hal tersebut, maka akan dibangun suatu implementasi kombinasi dalam pendukung keputusan penentuan kredit perumahan rakyat kepada calon konsumen berdasarkan data perumahan di kota Purwokerto dengan kriteria harga, desain, tipe, lokasi, fasilitas umum dan akses jalan. Dalam menentukan bobot pada setiap kriteria menggunakan metode AHP (Analytic Hierarchy Process) dan untuk menentukan rangking data perumahan menggunakan metode SAW (Simple Additive Weighting).

\section{METODE PENELITIAN}

Analityc Hierarchy Process (AHP) 


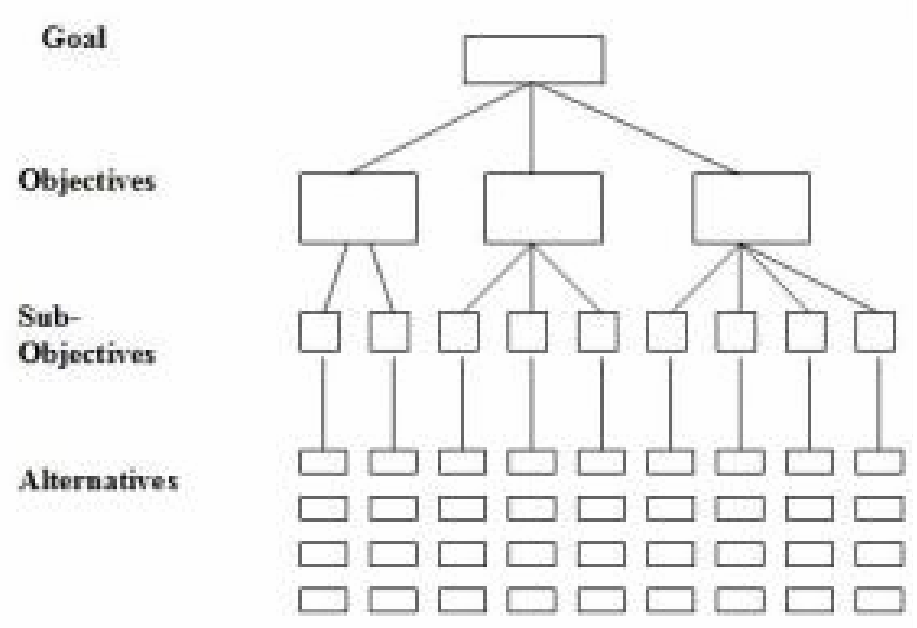

Gambar 1. Struktur Heirarcy AHP

Sumber : Iwan Rijayana (2012)

Terdapat beberapa langkah yang perlu diperhatikan dalam menggunakan metode AHP, antara lain Suryadi \& Ramdhani (1998):

a. Mendefinisikan masalah dan menentukan solusi yang diinginkan

b. Membuat struktur hirarki yang diawali dengan tujuan umum dilanjutkan dengan subtujuan-subtujuan, kriteria dan kemungkinan alternatif-alternatif pada tingkatan kriteria yang paling bawah

c. Membuat matriks perbandingan berpasangan yang menggambarkan kontribusi relatif atau pengaruh setiap elemen terhadap masing-masing tujuan atau kriteria yang setingkat diatasnya. Perbandingan dilakukan berdasarkan judgment dari pembuat keputusan dengan menilai tingkat kepentingan suatu elemen dibandingkan elemen lainnya.

Menurut Kusrini (2007) Skala penilaian perbandingan berpasangan, intensitas kepentingannya terdiri dari beberapa tingkatan yaitu

1) kepentingan dengan point 1 dengan keterangan kedua elemen sama penting.

2) Intensitas kepentingan dengan point 3 dengan keterangan elemen yang satu sedikit lebih penting daripada elemen yang lainnya. 
3) Intensitas kepentingan dengan point 5 dengan keterangan elemen yang satu lebih penting daripada elemen yang lainnya

4) Intensitas kepentingan dengan point 7 dengan keterangan satu elemen jelas lebih mutlak penting daripada elemen lainnya

5) Intensitas kepentingan dengan point 2,4,6,8 dengan keterangan nilai-nlai antara dua elemen yang satu sedikit lebih penting daripada elemen yang lainnya

d. Melakukan perbandingan berpasangan sehingga diperoleh nilai judgment seluruhnya yaitu sebanyak $n \times[(n-1) / 2$ ] buah dengan $n$ adalah banyaknya elemen yang dibandingkan

e. Menghitung nilai eigen dan menguji konsistensinya jika tidak konsisten maka pengambilan data diulangi

Dalam Saaty (2001), Nilai indeks random dapat dilihat sebagai berikut :

1) Ukuran matriks 1,2 maka nilai RI nya adalah 0.00

2) Ukuran matriks 3 maka nilai RI nya adalah 0.58

3) Ukuran matriks 4 maka nilai RI nya adalah 0.90

4) Ukuran matriks 5 maka nilai RI nya adalah 1.12

5) Ukuran matriks 6 maka nilai RI nya adalah 1.24

6) Ukuran matriks 7 maka nilai RI nya adalah 1.32

7) Ukuran matriks 8 maka nilai RI nya adalah 1.41

8) Ukuran matriks 9 maka nilai RI nya adalah 1.45

9) Ukuran matriks 10 maka nilai RI nya adalah 1.49

10) Ukuran matriks 11 maka nilai RI nya adalah 1.51

11) Ukuran matriks 12 maka nilai RI nya adalah 1.48

12) Ukuran matriks 13 maka nilai RI nya adalah 1.56

13) Ukuran matriks 14 maka nilai RI nya adalah 1.57

14) Ukuran matriks 15 maka nilai RI nya adalah 1.59

f. Mengulangi langkah 3, 4 dan 5 untuk seluruh tingkat hirarki 
g. Menghitung vektor eigen dari setiap matriks perbandingan berpasangan. Nilai vektor eigen merupakan bobot setiap elemen. Langkah ini untuk mensintesis judgment dalam penentuan prioritas elemen-elemen pada tingkat hirarki terendah sampai pencapaian tujuan.

h. Memeriksa konsistensi hirarki. Jika nilai lebih dari $10 \%$ (persen) atau 0,1 maka penilaian data harus diperbaiki.

\section{Simple Additive Weighting (SAW)}

Konsep dasar metode SAW adalah mencari penjumlahan terbobot dari rating kinerja pada setiap alternatif pada semua atribut. Metode SAW membutuhkan proses normalisasi matriks keputusan (X) ke suatu skala yang dapat diperbandingkan dengan semua rating alternatif yang ada (Kusumadewi, 2006).

Adapun langkah-langkah dalam metode SAW adalah sebagai berikut (Prayoko,2013):

a. Membentuk matriks dari setiap nilai kriteria.

b. Menormalisasikan nilai input dari kriteria tersebut.

c. Memberi nilai pembobotan pada setiap kriteria.

1) Keuntungan (Benefit).

2) Biaya (Cost).

d. Menentukan Perangkingan.

\section{HASIL DAN PEMBAHASAN}

Data-data yang dibutuhkan untuk menghasilkan suatu pendukung keputusan penentuan kelayakan dalam alternatif pilihan perumahan di Purwokerto berdasarkan kriteria yang paling dibutuhkan adalah sebagai berikut :

\section{Data alternatif perumahan}

Data Perumahan ini diambil dari data pilihan kredit perumahan rakyat (KPR) yang ada di area Purwokerto untuk dijadikan alternatif pilihan perumahan, yaitu : 
Tabel 1. Data alternatif perumahan

\begin{tabular}{|l|l|l|}
\hline No & Nama Perumahan & $\begin{array}{l}\text { Kode } \\
\text { Alternatif }\end{array}$ \\
\hline 1 & Oase Residence Purwokerto & h1 \\
\hline 2 & Griya asri karang salam & h2 \\
\hline 3 & Griya Satria Bukit Permata & h3 \\
\hline 4 & Griya Satria Bukit Nirwana & h4 \\
\hline 5 & Griya satria mandala tama & h5 \\
\hline 6 & Grand Satria Hill Keniten Purwokerto & h6 \\
\hline
\end{tabular}

\section{Data Macam Kriteria}

Banyak dari pengembang yang memberikan tawaran kriteria pemilihan rumah, namun disini penulis mengambil 6 macam kriteria yang akan digunakan untuk membantu dalam perengkingan data alternative perumahan yang disediakan, antara lain :

Tabel 2. Data macam kriteria

\begin{tabular}{|l|l|l|}
\hline No & Kriteria & Kode Kriteria \\
\hline 1 & Harga & s1 \\
\hline 2 & Desain & s2 \\
\hline 3 & Tipe & s3 \\
\hline 4 & Lokasi & s4 \\
\hline 5 & Fasilitas Umum & s5 \\
\hline 6 & Akses Jalan & s6 \\
\hline
\end{tabular}

\section{Analisa Perhitungan dengan Metode AHP}

\section{a. Menentukan bobot kriteria}

Dalam membuat matriks perbandingan beberapa kriteria, akan dijelaskan pada gambar 6 pada table data bobot prioritas dengan menentukan bobot dari tiap-tiap kriteria yang digunakan. 
Tabel 3. Data bobot prioritas

\begin{tabular}{|l|l|l|l|l|l|l|}
\hline & S1 & S2 & S3 & S4 & S5 & S6 \\
\hline S1 & 1 & 7 & 5 & 3 & 3 & 1 \\
\hline S2 & 0.143 & 1 & 0.714 & 0.333 & 1 & 0.143 \\
\hline S3 & 0.2 & 1.4 & 1 & 0.143 & 0.333 & 0.2 \\
\hline S4 & 0.333 & 3 & 7 & 1 & 1 & 0.333 \\
\hline S5 & 0.333 & 1 & 3 & 1 & 1 & 0.333 \\
\hline S6 & 1 & 7 & 5 & 3 & 3 & 1 \\
\hline total & 3.009 & 20.4 & 21.714 & 8.476 & 9.333 & 3.009 \\
\hline
\end{tabular}

\section{b. Menentukan nilai CI dan CR}

Dalam menggunakan metode Analytical Hierarchy Process diperlukan mengukur rasio konsistensi supaya diperoleh keputusan yang mendekati valid. Rasio konsistensi diharuskan kurang dari atau sama dengan $10 \%$.

Rumus yang digunakan mencari CI adalah sebagai berikut :

$$
C R=\frac{\lambda m a k s i m u m-n}{n-1}
$$

$\mathrm{CI} \quad=(6.384969-6) /(6-1)$

$=0.076994$

Tabel 4. Tabel Nilai RI

\begin{tabular}{|l|l|}
\hline $\mathrm{N}$ & $\mathrm{RI}$ \\
\hline 1 & 0.00 \\
\hline 2 & 0.00 \\
\hline 3 & 0.58 \\
\hline 4 & 0.90 \\
\hline 5 & 1.12 \\
\hline 6 & 1.24 \\
\hline
\end{tabular}

Sedangkan rumus yang digunakan untuk mencari CR adalah :

$$
C R=\frac{C I}{R I}
$$

$\mathrm{CR} \quad=0.076994 / 1.24$

$$
=0.062
$$


Dari hasil pencarian CR diperoleh nilai CR adalah sebesar 0.062 yang merupakan lebih kecil dari 0.1 sehingga hirarkrinyaa dinyatakan konsisten.

c. Menentukan matriks hasil bagi dari jumlah tiap kolom bobot prioritas

\begin{tabular}{|llllll|}
$\mathbf{0 . 3 3 2}$ & $\mathbf{0 . 3 4 3}$ & $\mathbf{0 . 2 3 0}$ & $\mathbf{0 . 3 5 4}$ & $\mathbf{0 . 3 2 1}$ & $\mathbf{0 . 3 3 2}$ \\
$\mathbf{0 . 0 4 7}$ & $\mathbf{0 . 0 4 9}$ & $\mathbf{0 . 0 3 3}$ & $\mathbf{0 . 0 3 9}$ & $\mathbf{0 . 1 0 7}$ & $\mathbf{0 . 0 4 7}$ \\
$\mathbf{0 . 0 6 6}$ & $\mathbf{0 . 0 6 9}$ & $\mathbf{0 . 0 4 6}$ & $\mathbf{0 . 0 1 7}$ & $\mathbf{0 . 0 3 6}$ & $\mathbf{0 . 0 6 6}$ \\
$\mathbf{0 . 1 1 1}$ & $\mathbf{0 . 1 4 7}$ & $\mathbf{0 . 3 2 2}$ & $\mathbf{0 . 1 1 8}$ & $\mathbf{0 . 1 0 7}$ & $\mathbf{0 . 1 1 1}$ \\
$\mathbf{0 . 1 1 1}$ & $\mathbf{0 . 0 4 9}$ & $\mathbf{0 . 1 3 8}$ & $\mathbf{0 . 1 1 8}$ & $\mathbf{0 . 1 0 7}$ & $\mathbf{0 . 1 1 1}$ \\
$\mathbf{0 . 3 3 2}$ & $\mathbf{0 . 3 4 3}$ & $\mathbf{0 . 2 3 0}$ & $\mathbf{0 . 3 5 4}$ & $\mathbf{0 . 3 2 1}$ & $\mathbf{0 . 3 3 2}$ \\
\hline
\end{tabular}

Dihasilkan rata-rata dari setiap kriteria adalah sebagai berikut :

$\begin{array}{lll}\text { S1 } & \text { (harga) } & =0.319 \\ \text { S2 } & \text { (desain) } & =0.054 \\ \text { S3 } & \text { (tipe) } & =0.05 \\ \text { S4 } & \text { (lokasi) } & =0.153 \\ \text { S5 } & \text { (fasilitas umum) } & =0.106 \\ \text { S6 } & \text { (akses jalan) } & =0.319\end{array}$

\section{Analisa Perhitungan dengan Metode SAW}

Dalam perhitungan menggunakan metode SAW akan dihasilkan perengkingan dari beberapa alternatif yang ada

Tabel 5.Data alternative perumahan

\begin{tabular}{|l|l|l|l|l|l|l|}
\hline $\begin{array}{l}\text { Kode } \\
\text { Alternatif }\end{array}$ & S1 & S2 & S3 & S4 & S5 & S6 \\
\hline H1 & 350000000 & 3 & 3 & 3 & 3 & 2 \\
\hline H2 & 200000000 & 3 & 3 & 4 & 3 & 3 \\
\hline H3 & 160000000 & 2 & 3 & 2 & 1 & 2 \\
\hline H4 & 450000000 & 3 & 3 & 4 & 1 & 3 \\
\hline H5 & 245000000 & 1 & 2 & 4 & 3 & 4 \\
\hline H6 & 185000000 & 4 & 3 & 4 & 3 & 4 \\
\hline
\end{tabular}

\section{a. Matriks Keputusan}




$\begin{array}{llllll}350000000 & 3 & 3 & 3 & 3 & 2 \\ 200000000 & 3 & 3 & 4 & 3 & 3 \\ 160000000 & 2 & 3 & 2 & 1 & 2 \\ 450000000 & 3 & 3 & 4 & 1 & 3 \\ 245000000 & 1 & 2 & 4 & 3 & 4 \\ 185000000 & 4 & 3 & 4 & 3 & 4\end{array}$

b. Normalisasi

$$
\begin{aligned}
& \mathrm{Y} 11=350000000 / 450000000 \\
& =0.778 \\
& \mathrm{Y} 21=200000000 / 450000000 \\
& =0.444 \\
& \text { Y31 }=160000000 / 450000000 \\
& =0.356 \\
& \mathrm{Y} 41=450000000 / 450000000 \\
& =1 \\
& \text { Y51 }=245000000 / 450000000 \\
& =0.544 \\
& \mathrm{Y} 61=185000000 / 450000000 \\
& =0.411 \\
& \mathrm{Y} 12=3 / 4 \\
& =0.75 \\
& \mathrm{Y} 22=3 / 4 \\
& =0.75 \\
& \mathrm{Y} 32=2 / 4 \\
& =0.5 \\
& \mathrm{Y} 42=3 / 4 \\
& =0.75 \\
& \mathrm{Y} 52=1 / 4 \\
& =0.25
\end{aligned}
$$




$$
\begin{aligned}
& \mathrm{Y} 62=4 / 4 \\
& =1 \\
& \mathrm{Y} 13=3 / 3 \\
& =1 \\
& \mathrm{Y} 23=3 / 3 \\
& =1 \\
& \mathrm{Y} 33=3 / 3 \\
& =1 \\
& \mathrm{Y} 43=3 / 3 \\
& =1 \\
& \mathrm{Y} 53=2 / 3 \\
& =0.667 \\
& \mathrm{Y} 63=3 / 3 \\
& =1 \\
& \mathrm{Y} 14=3 / 4 \\
& =0.75 \\
& \mathrm{Y} 24=4 / 4 \\
& =1 \\
& \text { Y34 }=2 / 4 \\
& =0.5 \\
& \mathrm{Y} 44=4 / 4 \\
& =1 \\
& \mathrm{Y} 54=4 / 4 \\
& =1 \\
& \mathrm{Y} 64=4 / 4 \\
& =1 \\
& \mathrm{Y} 15=3 / 3 \\
& =1 \\
& \mathrm{Y} 25=3 / 3 \\
& =1
\end{aligned}
$$




$$
\begin{aligned}
\text { Y35 } & =1 / 3 \\
& =0.333 \\
\text { Y45 } & =1 / 3 \\
& =0.333 \\
\text { Y55 } & =3 / 3 \\
& =1 \\
\text { Y65 } & =3 / 3 \\
& =1 \\
\text { Y16 } & =2 / 4 \\
& =0.5 \\
\text { Y26 } & =3 / 4 \\
& =0.75 \\
\text { Y36 } & =2 / 4 \\
& =0.5 \\
\text { Y46 } & =3 / 4 \\
\text { Y56 } & =0.75 \\
& =1 / 4 \\
& =4 / 4 \\
& =1 \\
&
\end{aligned}
$$

\section{c. Matrik Normalisasi}

$\left.\begin{array}{llllll}0.778 & 0.75 & 1 & 0.75 & 1 & 0.5 \\ 0.444 & 0.75 & 1 & 1 & 1 & 0.75 \\ 0.356 & 0.5 & 1 & 0.5 & 0.333 & 0.5 \\ 1 & 0.75 & 1 & 1 & 0.333 & 0.75 \\ 0.544 & 0.25 & 0.667 & 1 & 1 & 1 \\ 0.411 & 1 & 1 & 1 & 1 & 1\end{array}\right]$




\section{d. Pencarian Keputusan dan Rata-rata Rangking}

Proses ini dihitung menggunakan hasil rata-rata bobot prioritas dari yang telah diperoleh menggunakan metode AHP

$$
\begin{aligned}
\mathrm{V} 1= & (0.778 * 0.319)+(0.75 * 0.054)+(1 * 0.05)+(0.75 * 0.153)+ \\
& (1 * 0.106)+(0.5 * 0.319) \\
= & 0.601 \\
\mathrm{~V} 2= & (0.444 * 0.319)+(0.75 * 0.054)+(1 * 0.05)+(1 * 0.153)+ \\
& (1 * 0.106)+(0.75 * 0.319) \\
= & 0.652 \\
\mathrm{~V} 3= & (0.356 * 0.319)+(0.5 * 0.054)+(1 * 0.05)+(0.5 * 0.153)+ \\
& (0.333 * 0.106)+(0.5 * 0.319) \\
= & 0.4 \\
\mathrm{~V} 4= & (1 * 0.319)+(0.75 * 0.054)+(1 * 0.05)+(1 * 0.153)+ \\
& (0.333 * 0.106)+(0.75 * 0.319) \\
= & 0.721
\end{aligned}
$$

$$
\begin{aligned}
\mathrm{V} 5 & =(0.544 * 0.319)+(0.25 * 0.054)+(0.667 * 0.05)+(1 * 0.153)+ \\
& (1 * 0.106)+(1 * 0.319) \\
& =0.64
\end{aligned}
$$$$
\text { V6 }=(0.411 * 0.319)+(1 * 0.054)+(1 * 0.05)+(1 * 0.153)+
$$$$
(1 * 0.106)+(1 * 0.319)
$$$$
=0.601
$$

Hasil dari perhitungan diatas maka disusun perengkingan dari setiap alternatif, nilai tertinggi adalah dengan urutan sebagai berikut :
1) V4 (Griya Satria Bukit Nirwana) $=0.721$
2) V2 (Griya asri karang salam) $=0.652$
3) V5 (Griya satria mandala tama) $=0.64$ 

4) V1 (Oase Residence)
$=0.601$
5) V6 (Grand Satria Hill Keniten) $=0.601$
6) V3 (Griya Satria Bukit Permata) $=0.4$

\section{KESIMPULAN}

Kesimpulan yang dapat diambil dari analisis dan pengujian yang dilakukan pada bab sebelumnya adalah dalam penggunaan kombinasi metode Analityc Hierarchy Process (AHP) dapat memberikan bobot setiap kriteria dalam penentuan pilihan perumahan dan metode Simple Additive Weighting (SAW) mampu menentukan rangking data pilihan perumahan serta mampu memberikan kemudahan dalam penentuan pembelian rumah berdasarkan kebutuhan tiap konsumen.

\section{SARAN}

Saran yang dapat diberikan yaitu diharapkan dalam penelitian yang dapat dilakukan selanjutnya dapat menggunakan kriteria-kriteria yang lain dalam mempengaruhi penentuan alternatif pilihan perumahan yang ada.

\section{DAFTAR PUSTAKA}

Kusrini. (2007). Konsep dan Aplikasi Sistem Pendukung Keputusan.Yogyakarta: Penerbit ANDI.

Kusumadewi, Sri. (2006). Fuzzy Multi-Attribute Decision Making (Fuzzy MADM). Yogyakarta: Graha Ilmu.

Memariani, A., Amini, A. \& Alinezhad, A. (2009). Sensitivity Analysis of Simple Additive Weighting Method (SAW) : The Results of Change in the Weight of One Attribute on the Final Ranking of Alternatives. Journal of Industrial Engineering, vol. 2, no. 4: 13-18.

Prayoko, Mhd Riki. (2013). Sistem Pendukung Keputusan Penentuan Jurusan Pada Sekolah Menengah Atas SMA Setia Budi Abadi Perbaungan Dengan Menggunakan Metode Simple Additive Weighting (SAW). Jurnal Ilmiah Teknik Informatika STMIK Budi Darma Vol. V, No. 2, ISSN: 2301-9425.

Saaty, Thomas L. (1994). Fundamentals of Decision Making And Priority Theory Hierarchy Process, Vol. VI, RWS Publications. 
Suryadi, Kadarsah dan Rahmadhani. (1998). Sistem Pendukung Keputusan. Bandung : PT Remaja Rosdakarya 